\title{
Production of Polyclonal Antibody against Interleukin-33 and Assessment of Its Distribution in Murine Liver and Lung
}

\author{
Xiaojin Liu, Yan Wu, Mingcai Li, Sui Chen, and Yanchun Zhou \\ Institute of Inflammation and Immune Diseases, Shantou University Medical College, Shantou 515041, China \\ Correspondence should be addressed to Mingcai Li, mingcaili@yahoo.cn
}

Received 20 June 2009; Revised 11 August 2009; Accepted 6 September 2009

Recommended by Kostas Iatrou

\begin{abstract}
Interleukin (IL)-33 is the latest member of IL-1 cytokine family. In this study, the cloning, expression, purification, and polyclonal antibody preparation of mouse IL-33 were described. The coding region of IL-33 mature protein was cloned into the prokaryotic expression vector pET-44. The recombinant protein, IL-33 containing a hexahistidine tag in the C-terminal, was expressed in Escherichia coli. The expressed soluble protein was purified by immobilized metal-ion affinity chromatography using $\mathrm{Ni}^{2+}$ nitrilotriacetic acid agarose. The rabbits were immunized with the purified recombinant protein. The obtained antiserum was precipitated by saturated ammonium sulfate and then purified by Protein A affinity chromatography. The sensitivity and specificity of the antibodies were evaluated by enzyme-linked immunosorbent assay and immunohistochemistry. The high titer (1:32000) polyclonal antibodies with high specificity were obtained by immunizing rabbits with the purified recombinant protein. Significant expression of IL-33 was seen in mouse liver and lung tissues determined with the anti-IL-33. The production of the polyclonal antibody against IL-33 provides a good tool for studying the biofunctions of IL-33.
\end{abstract}

Copyright (C) 2009 Xiaojin Liu et al. This is an open access article distributed under the Creative Commons Attribution License, which permits unrestricted use, distribution, and reproduction in any medium, provided the original work is properly cited.

\section{Introduction}

The classical interleukin (IL)-1 family cytokines, IL- $1 \alpha$ and IL-1 $\beta$, as well as IL-18, are related by mechanism of origin, receptor structure, and signal transduction pathways utilized [1]. IL-33 (also named IL-1F11), which belongs to IL-1 family, is most closely related in structure to IL-18 and IL-1 $\beta$ [2]. IL-33 is also described as a nuclear factor expressed in high endothelial venules (NF-HEV) [3]. The human IL-33 gene is located on chromosome 9p24.1, while its mouse counterpart can be found on the syntenic chromosome $19 \mathrm{qC1}$ region [2]. The IL-33 cDNA sequences encode 270 and 266 amino acid polypeptides for human and mouse, respectively, corresponding to full-length proteins with calculated masses of 30 and $29.9 \mathrm{kDa}$ [2]. The proteins do not contain a signal sequence for secretion, similar to the IL- $1 \alpha$, IL- $1 \beta$, and IL-18 genes $[4,5]$. The precursor protein (pre-IL-33) was cleaved by caspase- 1 into a mature $18-\mathrm{kDa}$ protein (IL-33) in in vitro experiments using a recombinant protein [2]. Human and mouse IL-33 are 55\% identical at the amino acid level. IL33 signals via the IL-1 receptor-related protein ST2 $[2,6]$ and IL-1 receptor accessory protein [7] activate NF- $\kappa$ B and mitogen-activated protein kinases to induce $\mathrm{T}$ helper type 2 (Th2)-associated cytokines [2, 8, 9]. Administration of IL-33 to mice induces production of Th2 cytokines and severe pathological changes in mucosal organs [2]. Moreover, the ability of IL-33 to induce Th2 responses has functional relevance in the context of intestinal helminth infection [10]. IL-33 can promote survival, adhesion, and cytokine production in human mast cells [11], but the mechanism behind its involvement in inflammatory conditions remains unclear. Otherwise, IL-33 can reduce the development of atherosclerosis [12]. It is also a key mediator of immune inflammatory hypernociception normally associated with a Th1 type of response, revealing a hitherto unrecognized function of IL-33 in a key immune pharmacological pathway that may be amenable to therapeutic intervention [13]

In this study, the cloning and expression of mouse IL-33 gene in Escherichia coli (E. coli), purification of recombinant protein, and generation of polyclonal antibody against IL33 are described. The prepared antibody can be useful for the study of expression and distribution of IL-33 in various tissues at protein level and for the elucidation of its biofunctions and regulation mechanism in inflammatory diseases. 


\section{Materials and Methods}

2.1. Materials. E. coli strain BL21 (DE3) and Ni-NTA HisBind Resins were obtained from Novagen (Madison, WI). Trizol Reagent was purchased from Invitrogen (Carlsbad, CA). Hotstar Taq DNA polymerase and QIAquick Gel Extraction kit were purchased from Qiagen (Valencia, CA). PrimeScript first Strand cDNA Synthesis kit, restriction endonucleases $\mathrm{XhoI}$, NdeI, T4 DNA ligase, isopropyl- $\beta$-Dthiogalactoside (IPTG), DNA Marker D2000, and Protein Marker were from TaKaRa (Dalian, China). Lysozyme, complete Freund's adjuvant (CFA), and incomplete Freund's adjuvant (IFA) were obtained from Sigma (St. Louis, MO). New Zealand rabbits were from South Medical University (Guangzhou, China).

2.2. Plasmid Construction. Total cellular RNA was extracted from spinal cord of $\mathrm{BALB} / \mathrm{c}$ mouse according to Trizol Reagent instructions. The coding region of mouse IL-33 mature protein was amplified by reverse transcription polymerase chain reaction (RT-PCR). The first strand of cDNA was synthesized using the PrimeScript first Strand cDNA Synthesis kit, and the PCR reactions were carried out with a PTC-200 Peltier Thermal Cycler (MJ Research, Waltham, MA). The primer sequences of the IL-33 were designed with Primer Premier 5.0 software. Primer 1 (5'-GGAATTCCATATG ACATTGAGCATCCAAGGAAC- $\left.3^{\prime}\right)$ and primer $2\left(5^{\prime}-\right.$ CCGCTCGAGGATTTTCGAGAGCTTAAACA-3' ) were synthesized by Invitrogen (Shanghai, China). Primer 1 was synthesized with an NdeI site (shown in bold) and an additional ATG for initiation of translation in italicized style. Primer 2 was synthesized with an XhoI site (shown in bold). The amplification profile included one initial hot-start denaturation step at $94^{\circ} \mathrm{C}$ for 15 minutes, followed by 30 cycles of the following conditions: $94^{\circ} \mathrm{C}$ for 30 seconds, $57^{\circ} \mathrm{C}$ for 30 seconds, and $72^{\circ} \mathrm{C}$ for 1 minute, and a final extension at $72^{\circ} \mathrm{C}$ for 10 minutes. Plasmid pET-44 (Novagen, Darmstadt, Germany) was digested with NdeI and XhoI restriction enzymes. The large fragment was cut and purified from agarose gel using the QIAquick Gel Extraction kit. A recombinant plasmid was constructed by inserting the amplified fragments (also digested with NdeI and XhoI) into the NdeI and XhoI sites of pET-44 and transformed into E. coli strain BL21 (DE3). The transformants (pET-44mIL-33) were confirmed by colony PCR, restriction enzyme digestion, and DNA sequencing. Expression in bacteria results in the producing of recombinant IL-33 protein containing a hexahistidine tag in the C-terminus.

2.3. Expression and Purification of IL-33. A single colony of successfully transformed $E$. coli was picked up and cultured overnight at $37^{\circ} \mathrm{C}$ in Luria Bertani (LB) medium, supplemented with $100 \mu \mathrm{g} / \mathrm{mL}$ ampicillin. The culture mixture was then inoculated to fresh LB medium (1: 100 dilution) containing ampicillin and grown at $37^{\circ} \mathrm{C}$ under continuous shaking, until the absorbance at $600 \mathrm{~nm}$ reached $0.6-0.8$. To optimize the expression conditions, IL-33 expression was induced by adding $1 \mathrm{mM}$ IPTG to the transformed $E$. coli and the bacteria were incubated at $25^{\circ} \mathrm{C}$ for a period of $1,2,3,4,5,6,7,8$, and 9 hours, respectively. The degree of expression was evaluated by sodium dodecyl sulfatepolyacrylamide gel electrophoresis (SDS-PAGE). To compare the protein dissolubility, the bacteria with pET-44-mIL-33 were also incubated at $37^{\circ} \mathrm{C}$ or $25^{\circ} \mathrm{C}$.

After 7 hours of induction at $25^{\circ} \mathrm{C}$, the cells were harvested by centrifugation at $8,000 \times \mathrm{g}$ for 20 minutes at $4{ }^{\circ} \mathrm{C}$. The supernatant was discarded and the pellet was resuspended in lysis buffer consisting of $300 \mathrm{mM} \mathrm{NaCl}, 50 \mathrm{mM}$ $\mathrm{NaH}_{2} \mathrm{PO}_{4}, 10 \mathrm{mM}$ imidazole, $\mathrm{pH}$ 8.0, and lysed by using lysozyme, and incubated for 30 minutes at room temperature (RT) with gentle shaking to assure thorough cell lysis. The cell lysate was further disrupted by sonication on ice with six 10 -second pulses at high intensity with a 10 seconds cooling period between each burst. The suspension was centrifuged at $12,000 \times \mathrm{g}$ for 30 minutes to remove insoluble debris.

The supernatant was added to an Ni-NTA spin column pre-equilibrated with the lysis buffer, and then they were gently shaked on ice for 60 minutes. The flow-through was collected for SDS-PAGE analysis. The column was then washed with native wash buffer $(300 \mathrm{mM} \mathrm{NaCl}, 50 \mathrm{mM}$ $\mathrm{NaH}_{2} \mathrm{PO}_{4}, 20 \mathrm{mM}$ imidazole, $\mathrm{pH}$ 8.0). Finally, the bound protein was eluted with native elution buffer $(300 \mathrm{mM}$ $\mathrm{NaCl}, 50 \mathrm{mM} \mathrm{NaH}{ }_{2} \mathrm{PO}_{4}, 250 \mathrm{mM}$ imidazole, $\mathrm{pH}$ 8.0) and analyzed with $12 \%$ SDS-PAGE. Fractions were desalted and concentrated by an ultrafiltration device (Millipore Corporation, Bedford, MA). The concentration of IL-33 protein was determined by Lowry method. N-terminal sequencing was performed by automated Edman degradation method.

2.4. Production and Purification of Polyclonal Antibodies Against IL-33. The New Zealand white rabbits were given intradermal injections of IL-33 protein $(500 \mu \mathrm{g} / \mathrm{rabbit})$ mixed with CFA in $1: 1$ ratio. After 2 week, the rabbits were boosted subsequently 4 times with protein $(200 \mu \mathrm{g} / \mathrm{rabbit})$ mixed with IFA in $1: 1$ ratio at 2 -weeks interval. Before every immunization, blood samples were taken from the marginal vein of the rabbit ear, centrifuged, and the sera were obtained to determine the antibody titer by enzyme-linked immunosorbent assay (ELISA). One week after the last injection, antisera of the rabbits were collected and purified by saturated ammonium sulfate (SAS) and then Protein A Sepharose affinity chromatography (Amersham Biosciences, Piscataway, NJ) following manufacturer's instructions.

2.5. Antiserum Titer Determination by ELISA. The titer of antiserum was determined by an indirect ELISA. For each well of the 96-well ELISA plate, $200 \mathrm{ng}$ of IL-33 protein was diluted in $100 \mu \mathrm{L}$ of sodium bicarbonate solution and incubated overnight at $4^{\circ} \mathrm{C}$. After three washes with phosphate-buffered saline-(PBS-) Tween buffer $(0.05 \%$ Tween 20 in PBS), the wells were blocked using $100 \mu \mathrm{L}$ of $3 \%$ bovine serum albumin for 1 hour at $37^{\circ} \mathrm{C}$ and then incubated with $100 \mu \mathrm{L}$ polyclonal antibodies against IL-33 with different dilution (from $1: 100$ to $1: 64,000$ ) for 1.5 hours. The 
wells were incubated with $50 \mu \mathrm{L} /$ well horseradish peroxidase(HRP-) conjugated goat antirabbit immunoglobulin (IgG, $1: 250$ dilution) for 1 hour at $37^{\circ} \mathrm{C}$ after thoroughly washed. After final washes, $100 \mu \mathrm{L} /$ well tetramethyl benzidine (TMB) solution was added for color development. After 10 minutes, the reaction was stopped by $100 \mu \mathrm{L} /$ well $2 \mathrm{M} \mathrm{H}_{2} \mathrm{SO}_{4}$ and the absorbance was measured at $450 \mathrm{~nm}$ using a plate reader (Molecular Devices). Ratio of antiserum versus control serum absorbency greater than 2.1 was recognized as positive.

2.6. Immunohistochemistry. In order to confirm that the polyclonal antibodies are able to recognize IL-33 protein from tissues, immunohistochemistry was performed in normal $\mathrm{BALB} / \mathrm{c}$ mice lung and liver tissues. We also examined the IL-33 protein expression of plasmid pcDNA3.1-mIL-33 after delivery through hydrodynamics-based gene injection in BALB/c mice $[14,15]$. The plasmid pcDNA3.1-mIL-33 was constructed as forenamed, but whole mouse IL-33 cDNA was amplified by PCR and then inserted into mammalian expression plasmid pcDNA3.1(+) (Invitrogen). Twenty-four hours after plasmid injection, mice were anesthetized and sacrificed. Liver and lung were harvested and fixed in 10\% buffered formalin. After paraffin embedding, $5 \mu \mathrm{m}$ sections were cut. Immunohistochemistry on sections was performed as described previously with some modification [16]. Briefly, slides were dried in an oven $\left(60^{\circ} \mathrm{C}\right)$ before removing paraffin in several changes of xylene. Slides were hydrated through a series of graded alcohols to water, followed by incubation with $0.5 \%$ hydrogen peroxide for 5 minutes. Sections were incubated with $5 \%$ bovine serum albumin (BSA) in PBS for 10 minutes at RT to block nonspecific binding. After rinsing with PBS, slides were incubated overnight at $4^{\circ} \mathrm{C}$ with rabbit anti-IL-33 polyclonal antibody (1:1,000 dilution in PBS containing 5\% BSA). After rinsing with PBST (PBS containing $0.01 \%$ Triton X-100), tissue sections were incubated for 40 minutes at RT with HRP-conjugated goat antirabbit IgG $(1: 100)$ and rinsed with PBST. Subsequently, slides were stained with diaminobenzidine (DAB) and counterstained with hematoxylin, dehydrated, and mounted. Brown staining was considered positive. For negative control, normal rabbit serum or buffer alone were used in place of the primary antibodies.

\section{Results and Discussion}

3.1. Construction of Expression Plasmid pET-44-mIL-33. In order to express recombinant IL-33 in E. coli, the mature protein coding region of IL-33 was generated by PCR and was cloned between NdeI and XhoI sites of pET-44 vector containing the coding sequence for a hexahistidinecoding sequence in the C-terminal part. Amplification of the IL-33 gene by PCR produced a single amplified 480 bp DNA fragment, coding for a mature IL-33 protein of 160 amino acids. DNA sequencing revealed that the cDNA was the reported sequences. The final pET-44-mIL33 construct is able to express the recombinant IL-33 protein in fusion with a hexahistidine tag and allow for metal affinity purification.

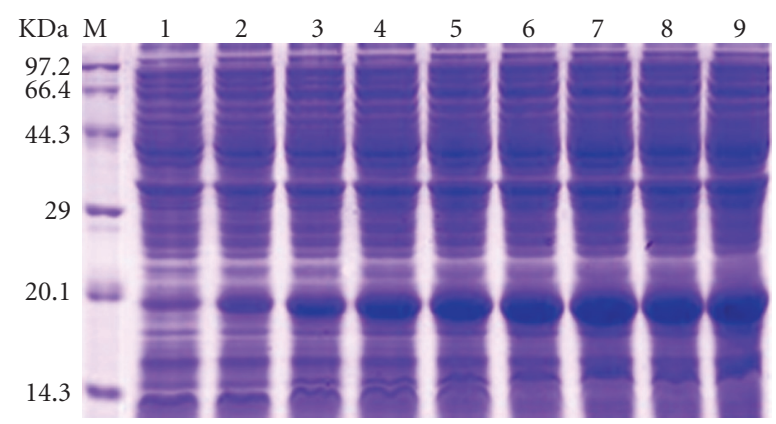

Figure 1: SDS-PAGE analysis of recombinant IL-33 protein expressed by $E$. coli. The expression was induced by $1 \mathrm{mM}$ IPTG at $25^{\circ} \mathrm{C}$ for different periods. Lane $\mathrm{M}$ : protein molecular weight marker; lanes 1-9: whole cell lysates after 1, 2, 3, 4, 5, 6, 7, 8, and 9 hours IPTG induction at $25^{\circ} \mathrm{C}$, respectively.

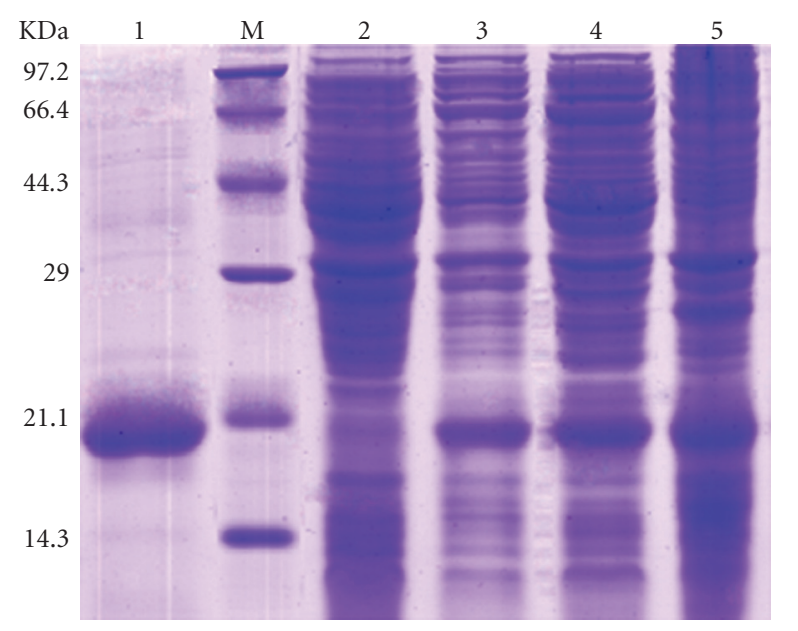

FIGURE 2: SDS-PAGE analysis of IL-33 purification and identification. Lane $M$, protein molecular weight marker; Lane 1: purified IL-33; Lane 2: total cell lysate before induction at $25^{\circ} \mathrm{C}$; Lane 3 : supernatant fractions of total cell lysate after induction; Lane 4: pellet fractions of total cell lysate after induction; Lane 5: total cell lysate after induction at $25^{\circ} \mathrm{C}$.

3.2. Expression of the Protein. After induction with IPTG, E. coli BL21 (DE3) transformed with pET-44-mIL-33 produced a protein of approximately $18 \mathrm{kDa}$ as shown in Figure 1. The size of the protein matched well with its theoretical molecular weight. To determine the optimal induction period, the bacteria were incubated with IPTG at $25^{\circ} \mathrm{C}$ for 1 , $2,3,4,5,6,7,8$, and 9 hours, respectively. The results showed that while the incubation period was below 7 hours, the yield of the $\sim 18 \mathrm{kDa}$ protein was increased as the induction time prolonged; but when the incubation time exceeded 7 hours, the yield of the product was not significantly raised (Figure 1).

3.3. Purification and Analysis of IL-33. The final concentration of IPTG used in this experiment was $1 \mathrm{mmol} / \mathrm{L}$, and the 


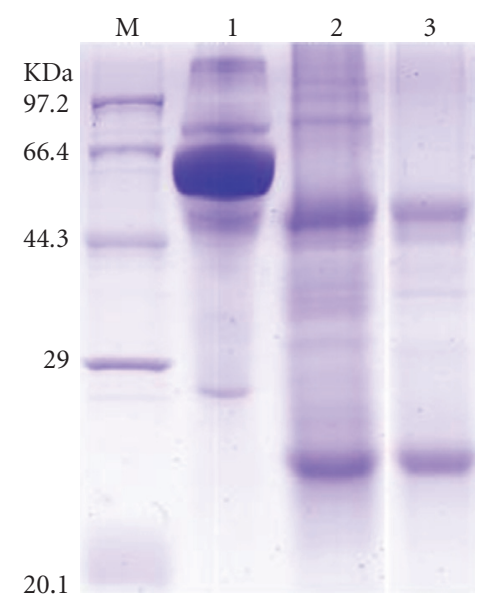

FIGURE 3: SDS-PAGE analysis of the polyclonal antibody. M: molecular weight marker; 1 : serum without purification; 2 : serum purified with SAS; 3: polyclonal antibody after purification by affinity chromatography.

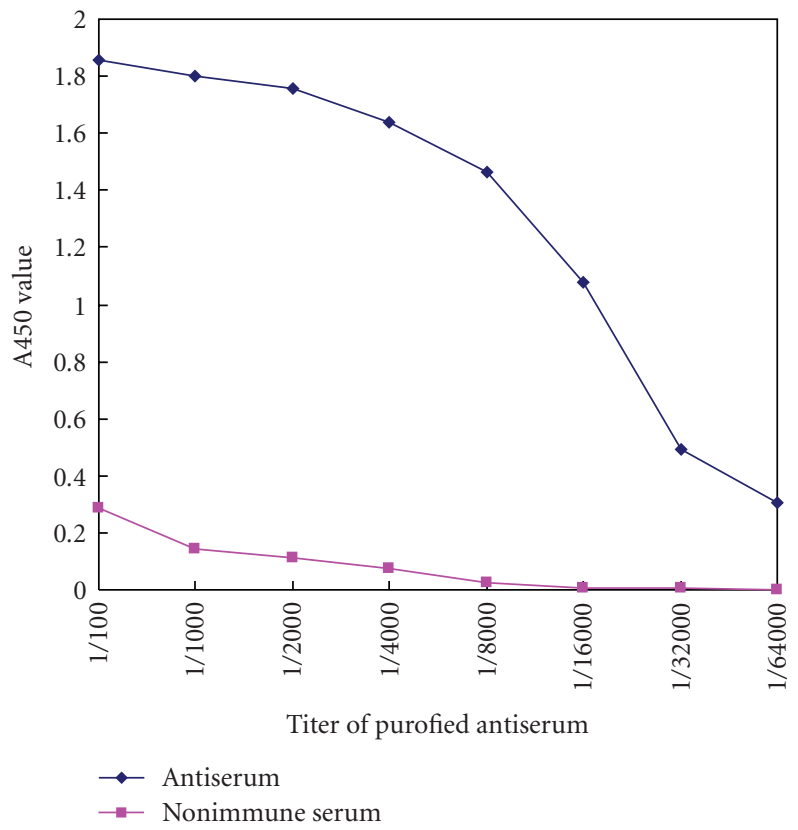

FIgure 4: The titer of antiserum by ELISA. The antibody titer is defined as the highest dilution of serum at which the A450 ratio (A450 of postimmunization sera/A450 of preimmunization sera) is greater than 2.1 .

bacteria were cultivated at $25^{\circ} \mathrm{C}$ for 7 hours. Induced BL2 1 (DE3) cells at $25^{\circ} \mathrm{C}$ can express the IL-33 protein (Figure 2, lane 5). In contrast, noninduced BL21 (DE3) cells did not express this fusion protein (Figure 2, lane 2). The soluble IL33 was expressed at high levels at $25^{\circ} \mathrm{C}$ (Figure 2, lane 3), but at low levels at $37^{\circ} \mathrm{C}$ (data not shown). This was most likely due to growth at $37^{\circ} \mathrm{C}$, which causes some protein to accumulate as inclusion bodies, whereas incubation at $25^{\circ} \mathrm{C}$ decreases the rate of protein synthesis and leads to soluble protein.

Ni-NTA affinity chromatography was applied for purification of the IL-33 fusion protein. The target IL-33 protein appeared as a single band on SDS-PAGE (Figure 2, lane 1), which is in agreement with the molecular weight reported [2]. Polyhistidine tags form high-affinity complexes with immobilized divalent metal ions ( such as $\mathrm{Ni}^{2+}$ or $\mathrm{Co}^{2+}$ ), even in the presence of high concentrations of chaotropic agents (e.g., urea or guanidine hydrochloride), thereby allowing isolation of tagged protein from a crude cellular extract [17]. His-tagged IL-33 exists in the bacterial cells in two forms: either soluble protein or inclusion bodies. The soluble protein was incubated with the Ni-NTA agarose slurry to allow binding of His-tagged IL-33. The purity of the protein as determined by densitometry was greater than $95 \%$. The yield of recombinant IL-33 was about $95 \mathrm{mg}$ from $1 \mathrm{~L}$ of bacterial culture. N-terminal sequencing of the purified IL-33 revealed that the first 20 residues were identical to the mouse IL-33 sequence deduced from the DNA (TLSIQGTSLLTQSPASLSTY).

3.4. Titer Analysis by ELISA. After immunizing rabbits with recombinant IL-33 according to standard protocol, anti-IL33 serum was purified by SAS precipitation and Protein A affinity chromatography. The purified antibody had high purity. The IgG fractions showed two bands, a heavy chain $(50 \mathrm{kDa})$ and a light chain $(25 \mathrm{kDa})$ on SDS-PAGE gel after passing through the Protein A-Sepharose column (Figure 3 ). The titer of the obtained anti-IL-33 serum was determined by ELISA. The antibody at different dilutions (100- to 64,000fold) was reacted with an equal amount of the IL-33 protein $(0.2 \mu \mathrm{g})$. The antibody titer is defined as the highest dilution of serum at which the A450 ratio (A450 of postimmunization sera/A450 of preimmunization sera) is greater than 2.1. The antibody titer was found to be approximately $1: 32,000$ (Figure 4).

3.5. Tissue Immunohistochemistry. IL-33 is a "dual-function" cytokine that may function as both an intracellular heterochromatin-associated nuclear factor and a potent proinflammatory cytokine [3]. After immunohistochemistry was performed using the anti-IL-33 polyclonal antibody in mouse lung and liver tissues, there were brown staining in nuclei or cytoplasm (Figures 5(b), 5(d), 5(f), $5(\mathrm{~h}))$. Furthermore, there was a significant increase of IL33 expression in hydrodynamics-injected mice with IL33 cDNA plasmid compared with normal mice (Figure 5). Bronchial epithelial cells in lung and liver cells revealed the strongest staining with anti-IL-33 antibody in hydrodynamics injected mice (Figures 5(h), 5(f)). No staining was detected in tissues where no antibody or control IgG was used in the primary layer (IgG control, Figures 5(a), 5(c), 5(e), 5(g)). Our results demonstrated that the endogenous IL-33 protein in tissues could be specifically recognized by our prepared anti-IL-33 polyclonal antibodies. 


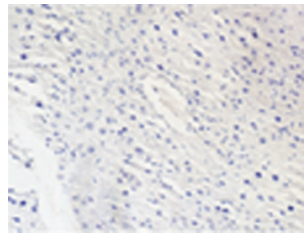

(a)

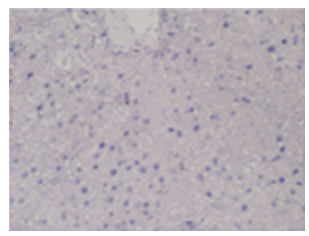

(e)

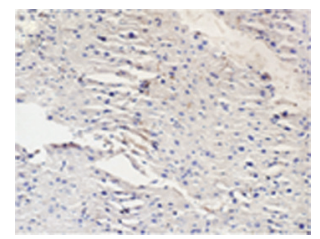

(b)

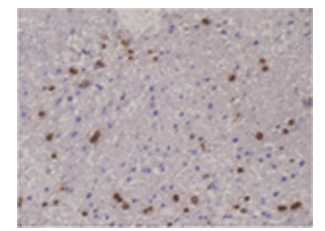

(f)

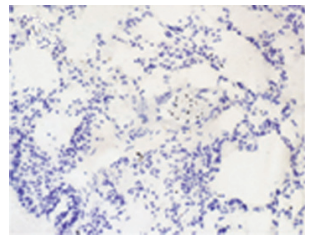

(c)

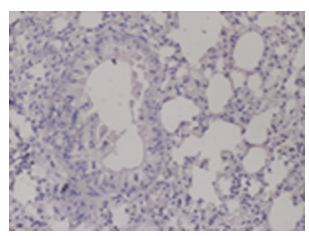

(g)

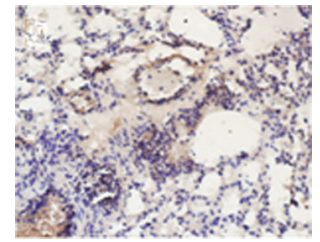

(d)

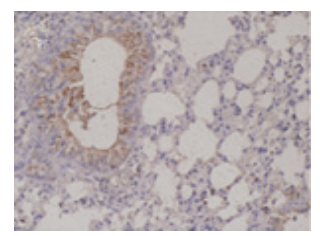

(h)

FIGURE 5: IL-33 immunostaining in mouse liver (a), (b), (e), (f) and lung (c), (d), (g), (h) tissues using the rabbit anti-IL-33 antibodies $(1: 1,000)$ under a microscope $(\times 400)$. Immunohistochemical analysis was performed in formalin-fixed, paraffin-embedded livers and lungs from normal mice and hydrodynamics-based gene injected mice after 24 hours $(n=4)$. Staining of IL-33 in livers and lungs from normal mice (b), (d) and hydrodynamics-injected mice (f), (h). Antibodies showed nuclear or cytoplasmic staining. Furthermore, there was a significant increase of IL-33 expression in hydrodynamics-injected mice (f), (h) compared with normal mice (b), (d). Control IgG showed no stain (a), (c), (e), (g).

\section{Conclusions}

We have developed a procedure for the efficient expression and purification of IL-33 using pET-44 vector and $\mathrm{Ni}$ NTA affinity chromatography. Furthermore, we report the production of specific anti-IL-33 antibody and the localization of endogenous IL-33. It has been observed that IL33 mRNA is broadly expressed in many tissues but is more restricted at the level of cell type, which includes pulmonary smooth muscle cells, epithelial cells, dermal fibroblasts, keratinocytes, dendritic cells, and activated macrophages [2]. IL-33 is also expressed in endothelial cells from chronically inflamed rheumatoid arthritis synovium and Crohn's disease intestine [3, 18] and atherosclerotic tissues [12]. However, very little information is available on the expression of IL33 protein in liver and lung tissues. To our knowledge this is the first report so far of production of polyclonal antibody against full-length mouse IL-33 and IL-33 protein expression in mouse liver and lung determined with anti-IL33 polyclonal antibodies. As IL-33 induces gene expression of Th2-associated cytokines and pathological changes in the lung [2], blockade of IL-33 may be a new therapeutic strategy for bronchial asthma. We are investigating the effect of exogenously administered anti-IL-33 antibody in a murine model of allergen-induced asthma [19] and collagen-induced arthritis. This research may contribute to elucidation of the biological mechanisms of IL-33 in human inflammatory diseases in the future.

\section{Acknowledgments}

This work was supported by the grants from the National Natural Science Foundation of China (Nos. 30671932, 30770840) to M. Li. The authors thank Ms. Xiaoxuan Zheng and Ms. Hanqiu Chen for their excellent technical assistance.

\section{References}

[1] W. P. Arend, G. Palmer, and C. Gabay, "IL-1, IL-18, and IL-33 families of cytokines," Immunological Reviews, vol. 223, no. 1, pp. 20-38, 2008.

[2] J. Schmitz, A. Owyang, E. Oldham, et al., "IL-33, an interleukin-1-like cytokine that signals via the IL-1 receptorrelated protein ST2 and induces T helper type 2-associated cytokines," Immunity, vol. 23, no. 5, pp. 479-490, 2005.

[3] V. Carriere, L. Roussel, N. Ortega, et al., "IL-33, the IL-1-like cytokine ligand for ST2 receptor, is a chromatin-associated nuclear factor in vivo," Proceedings of the National Academy of Sciences of the United States of America, vol. 104, no. 1, pp. 282-287, 2007.

[4] C. A. Dinarello, "Biologic basis for interleukin-1 in disease," Blood, vol. 87, no. 6, pp. 2095-2147, 1996.

[5] H. Tsutsui, K. Matsui, H. Okamura, and K. Nakanishi, "Pathophysiological roles of interleukin-18 in inflammatory liver diseases," Immunological Reviews, vol. 174, pp. 192-209, 2000.

[6] H. Hayakawa, M. Hayakawa, A. Kume, and S.-I. Tominaga, "Soluble ST2 blocks interleukin-33 signaling in allergic airway inflammation," The Journal of Biological Chemistry, vol. 282, no. 36, pp. 26369-26380, 2007.

[7] G. Palmer, B. P. Lipsky, M. D. Smithgall, et al., "The IL1 receptor accessory protein $(\mathrm{AcP})$ is required for IL-33 signaling and soluble AcP enhances the ability of soluble ST2 to inhibit IL-33," Cytokine, vol. 42, no. 3, pp. 358-364, 2008.

[8] C. A. Dinarello, "An IL-1 family member requires caspase-1 processing and signals through the ST2 receptor," Immunity, vol. 23, no. 5, pp. 461-462, 2005.

[9] M. Komai-Koma, D. Xu, Y. Li, A. N. McKenzie, I. B. McInnes, and F. Y. Liew, "IL-33 is a chemoattractant for human Th2 cells," European Journal of Immunology, vol. 37, no. 10, pp. 2779-2786, 2007.

[10] N. E. Humphreys, D. Xu, M. R. Hepworth, F. Y. Liew, and R. K. Grencis, "IL-33, a potent inducer of adaptive immunity to intestinal nematodes," The Journal of Immunology, vol. 180, no. 4, pp. 2443-2449, 2008. 
[11] M. Iikura, H. Suto, N. Kajiwara, et al., "IL-33 can promote survival, adhesion and cytokine production in human mast cells," Laboratory Investigation, vol. 87, no. 10, pp. 971-978, 2007.

[12] A. M. Miller, D. Xu, D. L. Asquith, et al., "IL-33 reduces the development of atherosclerosis," Journal of Experimental Medicine, vol. 205, no. 2, pp. 339-346, 2008.

[13] W. A. Verri Jr., A. T. Guerrero, S. Y. Fukada, et al., "IL33 mediates antigen-induced cutaneous and articular hypernociception in mice," Proceedings of the National Academy of Sciences of the United States of America, vol. 105, no. 7, pp. 2723-2728, 2008.

[14] F. Liu, Y. Song, and D. Liu, "Hydrodynamics-based transfection in animals by systemic administration of plasmid DNA," Gene Therapy, vol. 6, no. 7, pp. 1258-1266, 1999.

[15] G. Zhang, V. Budker, and J. A. Wolff, "High levels of foreign gene expression in hepatocytes after tail vein injections of naked plasmid DNA," Human Gene Therapy, vol. 10, no. 10, pp. 1735-1737, 1999.

[16] F.-R. Zhang, L.-H. Tao, Z.-Y. Shen, Z. Lv, L.-Y. Xu, and E.-M. $\mathrm{Li}$, "Fascin expression in human embryonic, fetal, and normal adult tissue," Journal of Histochemistry and Cytochemistry, vol. 56, no. 2, pp. 193-199, 2008.

[17] K. Glynou, P. C. Ioannou, and T. K. Christopoulos, “Onestep purification and refolding of recombinant photoprotein aequorin by immobilized metal-ion affinity chromatography," Protein Expression and Purification, vol. 27, no. 2, pp. 384-390, 2003.

[18] G. Palmer, D. Talabot-Ayer, C. Lamacchia, et al., "Inhibition of interleukin-33 signaling attenuates the severity of experimental arthritis," Arthritis and Rheumatism, vol. 60, no. 3, pp. 738-749, 2009.

[19] X. Liu, M. Li, Y. Wu, Y. Zhou, L. Zeng, and T. Huang, "AntiIL-33 antibody treatment inhibits airway inflammation in a murine model of allergic asthma," Biochemical and Biophysical Research Communications, vol. 386, no. 1, pp. 181-185, 2009. 


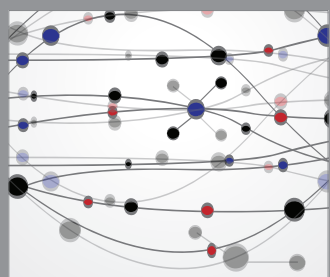

The Scientific World Journal
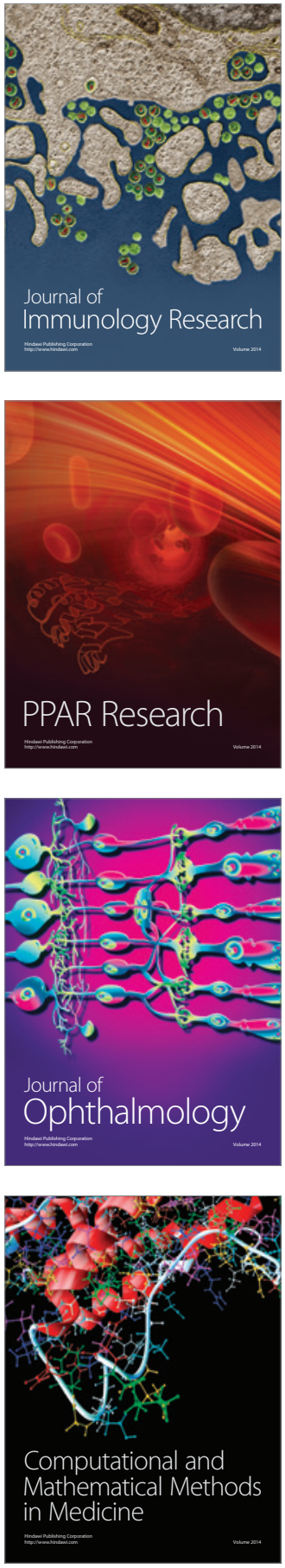

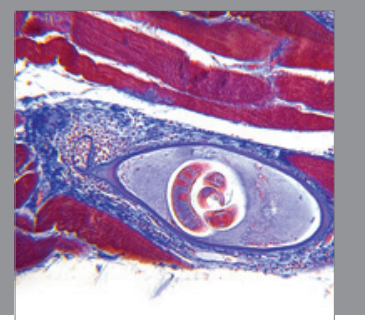

Gastroenterology

Research and Practice
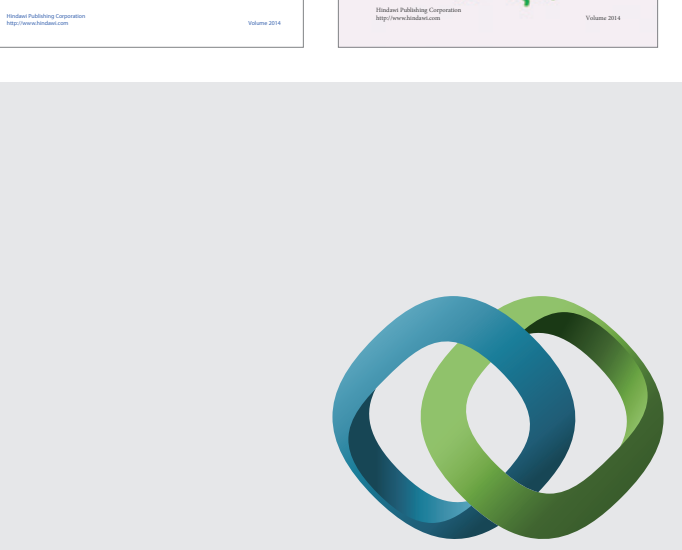

\section{Hindawi}

Submit your manuscripts at

http://www.hindawi.com
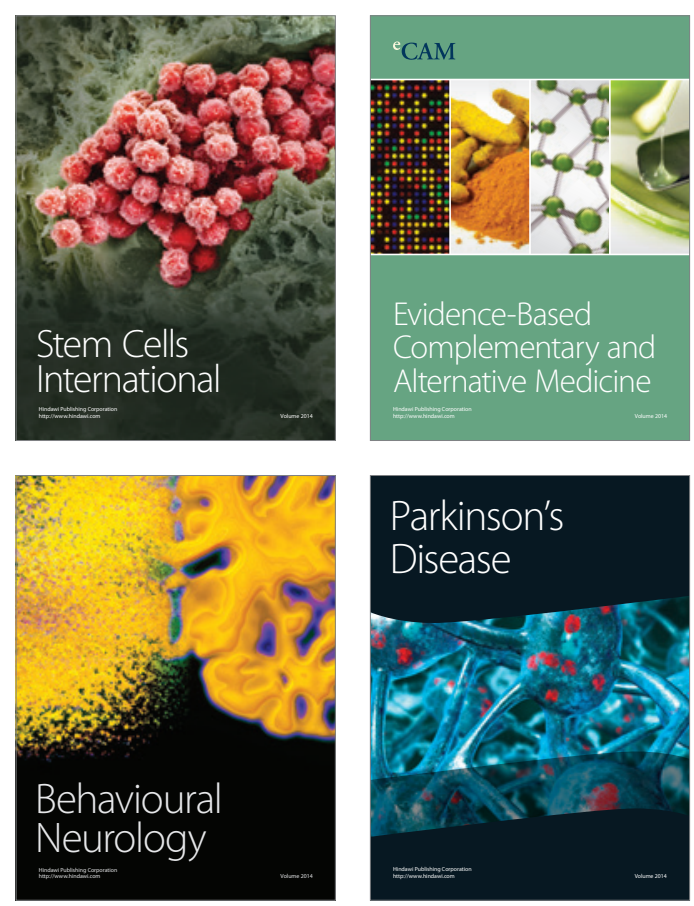

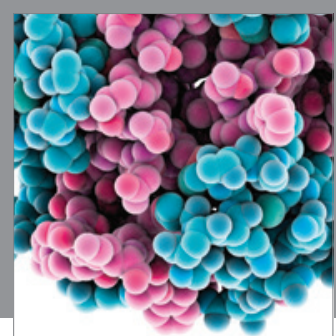

Journal of
Diabetes Research

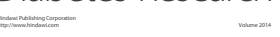

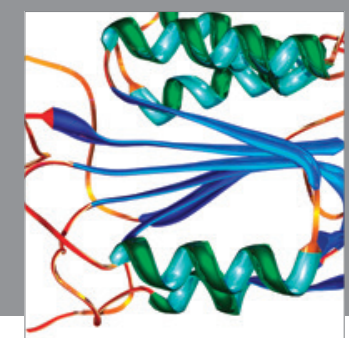

Disease Markers
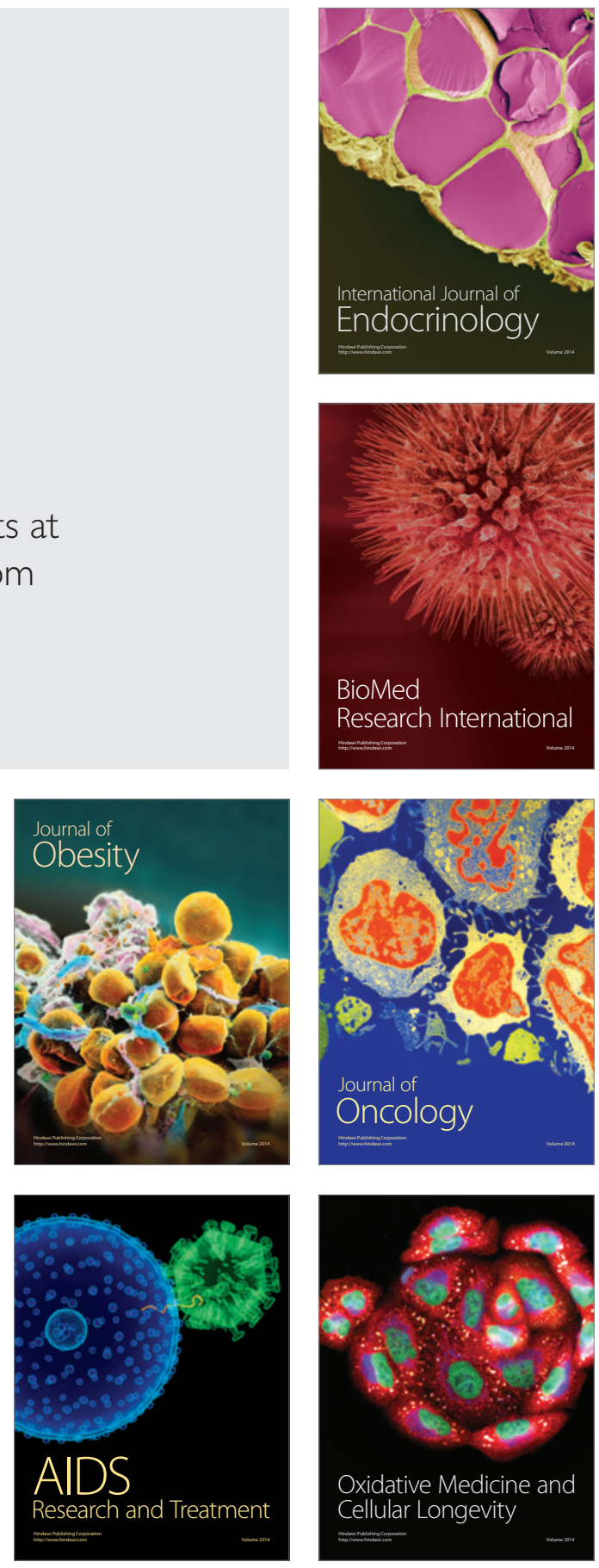